\title{
Progress in Ecology: Fact or Fiction?
}

\author{
Jerzy Wolek \\ Pedagogical University of Cracow, Faculty of Geography and Biology, \\ Institute of Biology, Podchorążych 2, 30-084 Kraków, Poland \\ e-mail: jwolek@ap.krakow.pl
}

\begin{abstract}
The paper focuses on the criteria for the assessment of the progress in ecology and attempts to respond to the question how to achieve the progress in ecological research? As regards the first issue, the author suggests two criteria, which he finds an easy to determine measure of progress. They include the following: a number of resolved issues and the existing progress in perfecting the ecological terms. With respect to the latter issue, the author specifies six critical recommendations on the basis of literature data and cited opinions of several researchers. According to him, their application would make it possible to achieve an unquestionable progress in ecology.
\end{abstract}

Key words: criteria for progress, quantitative progress measure, ecological terminology, pluralism in ecology, research hypotheses, principles of scientific methodology.

\section{Introduction}

Ecology has its roots in natural history, which is as old as human beings (McIntosh 1985), however, the ecological issues were recognised as a separate branch of knowledge (scientific discipline) by Ernst Haeckel, who developed the term ecology in 1866 and defined it as the total relations between an animal and both its organic and inorganic environment. Thus, the year of 1866 might be recognized as a reference point for the passage of historical time of ecology.

During over 130 years of ecology, a number of its sub-branches have emerged and each one of them has developed its own research hypotheses and theories, and research methods. The time when an ecologist could be a specialists in all ecological issues has long passed. Therefore, when somebody talks about ecology, one focuses on their own research experience and comments familiar issues and studied subjects.

\section{Criteria for the assessment of progress in ecology}

Similarly to the other fields of knowledge, the progress in ecology may be assessed with the use of various criteria, e.g. based on the amount of information collected. However, I believe that the best way to measure it is: (1) by a number of key problems, which have been solved and (2) by assessing the progress in perfecting the terms. Those criteria resulting directly from detailed methodological solutions in a given branch of science constitute an easy to define index of progress. They can help to test the hypothesis whether there is any progress in a given branch of science.

Criterion 1: The number of solved problems

Although it seems there is certain progress with respect to certain specific issues, we do not witness any major progress in our understanding of the fundamental ecological processes: there are still discussions under way about the very same questions as years ago (Weiner 1995). Ac- 
cording to Łomnicki (1980), none of the problems have been solved entirely, so that it could become a law, a principle or a rule. Optimists believe that the diversity of theories, hypotheses, models reflects the diversity of nature (Silvertown 1982), however, it seems that it rather reflects the chaos occurring with respect to theoretical bases and terminology.

That is best illustrated by the never-ending controversies between advocates of the organism (Clements 1916, 1928, 1936) and individualistic (Gleason 1917, 1926, 1939) concepts. For ninety years ecologists have been asking whether non-random structure patterns exist. When in 1968 the esteemed ecologists expressed their opinions on the continuum concept in The Botanical Review, Lieth (1968) wrote: „It is really sad to read Scharferetter's, Drude's, and especially du Rietz's discussions. They use the same terminology and have nearly the same problems as we do". The discussion that Lieth referred to had taken place in the early 1930s.

The so-called assembly rules are related to the aforementioned issues - for the first time suggested by Diamond (1975) and then called into question by Connor and Simberloff in 1979. For over thirty years, researchers have been searching for evidence of the existence of any rules controlling the development of plant and/or animal communities (Gotelli \& MacCabe 2002; Ulrich 2004; Ulrich \& Gotelli 2007).

Since the time of Clements (1904), ecologists have been ascribing an important role to competition in controlling the community structure and dynamics, and in spite of the fact, responses to the fundamental questions are still lacking. One hundred years have passed and yet there is no agreement among researchers with respect to the existence and significance of competition in biological systems. According to some researchers (Grime 1979; Tilman 1988), credible evidence may be found indicating the existence of competition in the nature and its important role in the organisation of biocoenoses. In contrast, other researchers (Hairston et al. 1960; Connor \& Simberloff 1979, 1983; Simberloff 1983; Austin 1990) believe that all the available data show animals and plants to avoid competition and thus interaction of that type is not the main controlling ecological force.

The problem, which has not been solved for almost 70 years is the role of density-dependent population processes (Lawton 1991). There are more examples of that type.

Actually, in spite of applying more and more sophisticated research methods and mathematical apparatus, the ecological issues mentioned above and also other issues have remained unsolved due to ambiguous research results. The approval to such opinions still depends mainly on the status of a researcher in his/her milieu, as well as on the current fashion, belief or other non-contents related rationale. Another worth mentioning issue is the fact that the majority of what is called the "ecological theory" is not a theory at all (Peters 1991).

Criterion 2: Progress in perfecting the ecological terms

Progress in ecology (as in the whole science) depends on clear-cut, non-ambiguous definitions of the applied terms (Mason \& Laugenheim 1957; McIntosh 1967; Austin 1968; Peet 1974; Chapleau et al. 1988). Although the clear-cut terminology is the key issue (Loehle 1988), one can see that the meaning of the applied terms is recognized as commonly known all too often and therefore not enough attention is paid to them. Under the circumstances, one can respond to the question about the terms that have been perfected so that have been commonly recognized and accepted by the ecologists' milieu that such terms do not exist. That statement is easy to verify when taking a look at any review article, each one of them starting from a comment that the definition of the phenomenon in question is not unambiguously specified. (Here the question arises: If nobody knows what the discussion subject is, how can anybody express any responsible opinions of it?) Certainly, some authors do recognise the issue of terminology and there are attempts made to improve the situation (see Chapleau et al. 1988; Loehle 1988; Wilson et al. 1992). On the other hand, those attempts have not improved the present situation. Bellow you can find a number of ecological terms and those used in ecology, whose definitions have not been established in a clear-cut manner: competition (Risser 1969; Grime 1979; Thompson 1987; Tilman 1987, 1988; Keddy 1989), an individual (Falińska 1990), population (Jonckers 1973), ecotone (Matejka 1992), patch (Wiens 1976; Pickett \& White 1985), diversity (Peet 1974), guild (Simberloff \& Dayan 1991), ecosystem (Golley 1993), strategy, pattern, process and mechanism (Rejmanek 1977; Chapleau et al. 1988; Anand 1994).

Eiten (1992) shows how differently names might be used for defining various vegetation types. There are no fixed criteria. Plant communities are distinguished on the basis of various criteria, which makes them incomparable and they differ in their status. Often the same name is used to for defining different vegetation types. Eiten noted that vegetation types are defined with six combinations of three basic criteria, that is physiognomy, floristic composition and habitats.

The use of ambiguous terms brings about misunderstandings and never-ending discussions. This results from the fact that every term, every concept and every name comprises specific content being its concealed definition. As very often individual terms are developed with the use of colloquial names, each one conveys some meaning (there are no "blank" names). If the meaning of a given term is not expressed in a clear-cut manner, then every user of the term ascribes his or her own meaning resulting 
from personal experience, observations, knowledge, etc. If an author uses imprecise terms and additionally makes implied assumptions whose number and character are not specified, a reader has to surmise "what did the author mean". Such interpretation of an original text is very deceptive and may lead do misunderstandings. A spectacular example of such a situation is The Structure of Scientific Revolutions by Kuhn (1968). The author himself admitted that sometimes he could not believe that all the readers of his book, he talked to, had read the very same text (Kuhn 1985). He admitted he felt sorry that the success of his book partly resulted from the fact it might be understood in various ways. Kuhn was aware that his book's ambiguity was due to introduction of the word paradigm. The reviewers agreed that numerous meanings of the term were used, according to one of them - as many as 22 various meanings were used.

It seems that some authors are not entirely aware of the consequences of imprecise terms. Reisser (1969) published a review related to competition in meadow plants. In that paper, the author stressed a very large number of various definitions of competition, referred a reader to original papers and then started to review papers dedicated to competition between plants. How he did it when comparing the material so diverse in the terms of methodology, without trying to smooth away those differences, will remain a mystery to me. A similar method was applied by Keddy (1989) in his book on competition - although he did present his own definition of competition, later in the book that appeared to be a purely formal effort.

And the final example of such an attitude is a review of the Symposium on Minimum Populations that took place in Bad Hamburg, Germany between 25 and 28th September, 1991, published in Wiadomości Ekologiczne 38(2). As the reviewing authors mentioned, after the conference, during their free time, the participants had initiated a discussion on the definition of a minimum population; they had discussed whether a small population meant a population with small numbers or rather low density. I believe no comment is necessary here in the light of the issues mentioned above.

Thus, bearing in mind the assumed criteria, the progress in ecology should be assessed negatively. First, during 140 years of the existence of ecology none of the important ecological problem has been finally solved - apart from collecting an immense body of observations that actually yields few effects (see Krebs' 1972, note on data collection). Second, we keep on using imprecise, ambiguous concepts, which only increase the information noise and make the communication difficult.

\section{How to achieve the progress in ecological research?}

Researchers often wonder why there is no significant progress in ecology and what should be done to obtain theories, which would improve our understanding of ecological processes and have predictive power in the field of ecology. Below there is a review of some publications concerning that issue. Although it is not a complete list of discussion participants, one can assume that the presented opinions constitute a representative review of views, as they constitute the leitmotif of the ecological literature. The presented opinions made it possible to recognise six main recommendations, which according to their authors would enable to achieve the unquestionable progress in ecology.

Recommendation 1: Ecology requires sound theoretical bases and the practice requires solid support in the theory

It is often claimed that theoretical bases of ecology are weak and there are no laws in ecology - erroneous interpretation of ecological principles as laws has been constituting a long-lasting problem in ecology. Picektt and Kolasa (1989), as well as Scheiner et al (1993) and others believe otherwise. Personally, I do not share their optimism. I think that ecology should do a lot with respect to theoretical bases (which are of key importance to empiricism). The situation is hardly satisfactory as clear-cut, generally accepted statements in relation to philosophical and methodological bases are still lacking. According to Kuhn (after McIntosh 1975), science can effectively develop when the consensus about four questions is achieved:

- what are the fundamental beings that make up the Universe?

- how those beings affect one another?

- what are the justified questions about such beings?

- what techniques might be applied to search for solutions?

According to the opinion by McIntosh (1975), which I share, ecology fails to deal successfully with the first question and if the first issue is not solved, answering the other three is impossible, too.

Another issue are the theories themselves. Loehle (1983) believes that a good theory should not only predict but also explain. An important role in developing the explanatory theories might be played by (1) search for patterns and their analysis and (2) construction of deductive mathematical models (Weiner 1995).

In the first case, data collection through following some ecological idea is helpful. However, if that activity is not related to verification of a specific research hypothesis or does not aim at searching for patterns, then it becomes from the scientific point of view - a senseless waste of 
time. That is so because the collected data might never be used or will be used to a small extent only. Weiner (1995) stresses that ecological data are often collected and treated as the so-called case studies (reports with detailed information on some object or groups of objects), which are then used for "causative stories", making us feel we understand processes and phenomena. According to him, phytosociologists continue to describe and classify vegetation types for the sake of art, although the biological significance of categories and their contribution to understanding the processes in vegetation is questionable. Certainly, certain amount of empirical knowledge is necessary before we could say anything about a studied system and description of individual cases is necessary before we can find patterns, but the question arises in this context - how many case studies might be reasonably justified (Weiner 1995).

One should mentioned here a common research attitude characterised by neglecting theoretical and methodological bases of the studied problem, while planning a study. All too often authors forget that the so-called "bare facts" do not exist, that "every fact is soaked with theory" (e.g. Heller 1992). Also all too often authors forget that without any methodological framework they cannot make any decision while interpreting the results obtained. If that framework is not explicit, a researcher will make use of implied assumptions (usually being unaware of that).

As regards the second case mentioned above, Weiner (1995) suggests that one of the main reasons why theoretical studies in ecology do not provide any testable predictions is the fact that theories often fail to refer to patterns occurring in nature and instead concern abstract issues. According to the aforementioned author, whose opinion is shared by Lawton (1991), both theoretical and empirical studies often tend to follow their internal logics instead of attempting to solve scientific problems. Therefore, such an attitude should be rejected and replaced with close cooperation between theoreticians and empiricists - a combination of theory and practice should be pursued.

Recommendation 2: Ecologists should focus on putting precise questions

Keddy (1987) believes that the progress in ecological research, specifically in ecology of communities, depends mainly on the type of questions posed and a choice of appropriate variables that should be measured in order to obtain a proper answer to a question. However, the author admits that unfortunately it is not quite clear what questions should be asked and which variables should be investigated. According to him, one of the examples of poorly formulated questions is the question about the controversy over the continuum vs. community unit concept (see also Shipley \& Keddy 1987), as it is posed in a nontestable form. This means that it refers to a concept (which is non-testable) instead of a hypothesis, which might be falsified (see Peters 1980). Based on the analysed papers concerning that very controversy published in the last decades, Keddy (1987) suggests that Stearns (1976) and Peters (1980) are right in their conclusion that we have become modern scholastics who endlessly discuss issues that cannot be solved or scientifically tested.

Too little attention focused on the precision of questions might result from the easiness of data collection. As Keddy (1989) writes, there exist a temptation to designate squares in the field, in which some observations on plants and/or vegetation are carried out, just to find what will happen or hoping that one day the collected data might be useful to someone.

Neither a description nor new statistical methods alone can produce the progress. Both a description and statistical analysis have to follow a certain idea which will make it possible to target those activities at certain specific, scientific aim. So, Keddy (1989) ironically proposes to leave our squares for a few years and then try to decide which questions we should try to answer first. Perhaps then, the ecology would develop faster than now.

\section{Recommendation 3: Ecologists should observe principles of reasoning peculiar to physics}

According to Murray (1992), the reason for which ecologists (or more broadly - biologists) do not produce commonly approved, explanatory and predictive theories is much deeper - biologists do not think the same way as physicians do.

According to Dyson (1988), biologists are people who love to study details. They are happy when they may leave the world just a little bit more complicated than it used to be before their research. Dyson called them diversifiers those who diversify. In contrast, physicians are those who are fond of finding general rules that explain everything. Dyson call them unifiers - those who unify.

Therefore, biologists asked to investigate the movement of a cart would never be able to discover inertia as they would rather focus on designing experiments aiming at determining the role of factors inhibiting the movement. Murray (1992) draws attention to the fact that biologists have the erroneous idea about the precision of models developed by physicists. Few people are aware that Newton developed his theory of the universe for two bodies: one planet revolving around one star and that Newton was aware of his theory restrictions (see also Werle 1992 and Stewart 1997).

Development of the concepts in physics dates back to the time of Galileo and Newton, who discovered and applied a new manner of scientific reasoning, and whose four rules, valid also today, were prepared by Newton (Einstein \& Infeld 1938, after Murray 1993; Werle 1992). Murray 
(1992) suggests that biologists are still in the pre-GalileoNewton era in terms of solving the scientific problems and perhaps this is the reason for their failures.

A different opinion was presented by Quenette and Gerard (1993). According to them, biologists cannot follow Newton's rules of reasoning since biological systems are non-linear, non-Newton systems. Because of the chaotic dynamics, they are characterised by sensitivity to initial states (history of a system becomes important!) and hence, unpredictability over longer time periods. The Markov process is a different case, in which a given future state, at any given moment, depends only on its present state, and not on any past states. Therefore, Murray's recommendations may be used rather for directing than improving our understanding of evolution of living beings.

Although we do not deal with linear systems in ecology and we have to accept the fact that ecological processes will never be as predictable as physical or chemical processes, many authors believe that the way the ecology is practised may in fact be the reason for failures in developing sound theories.

\section{Recommendation 4: Ecology should be pluralistic}

The idea of pluralistic ecology have already been presented several times (Strong et al. 1984; Abrahamson et al. 1989; Murdoch et al. 1992; Weiner 1995). Since ecology is a young science and we still do not know which approach will produce the real progress, we should try various approaches - ecology needs new ideas, hypotheses and theories. The pluralistic approach assumes rejection of general theories, which are not successful in generating any testable hypotheses, and replacing them with theories developed for small portions of nature similarly to what has been done in medicine - a drug for treating all diseases has not been found but a considerable progress has been achieved in treating certain disease classes. Pluralism means less impressive but more useful ecology (Weiner 1995).

Recommendation 5: When teaching the ecology, stress should be put mainly on research approaches and not on facts

Students should be taught mainly various research approaches, presentation of facts should be stressed to a lesser degree. Also, special attention should be paid to arousing the sense of scepticism and criticism of current ecology achievements (Weiner 1995). I'm inclined to agree with that opinion. Presenting the ecology as a science, which is perfect in almost all the aspects and equipped with tested and commonly accepted theories, bring fatal results to it. Researchers with such a background will contribute nothing new to science, all their lives just repeating schemes acquired during their studies. If they ever awaken, years will pass.

To an extent larger than today, all the assumptions mentioned above should be included into curricula of would-be ecologists and this should be done mainly in their practical, instead of abstractive dimension.

\section{Recommendation 6: Ecological terms should be defined in an operative manner}

The response to terminological problems is the call to define ecological terms in an operative manner (Loehle 1988; Peters 1991) - a researcher must not present terms in a loose manner, which is typical of vocabulary definitions. An operative definition should determine conditions and procedures making it possible to present an idealised response to a given question about a defined term. And thus, we should specify all which we are to observe in an operative definition, determine in what conditions (constant or variable) observations should be made, what types of operations should be performed, what instruments and measures should be applied and how the observations should be carried out and how their results should be interpreted (Ackoff 1969).

\section{Conclusions}

Among the presented recommendations, deserving the comprehensive support and the most important seems to be the one related to arranging and following the operatively defined terminology. I believe that this issue is of key importance, as the effect of observing the other recommendations depends to a large extent, if not entirely, on the way the applied terms are defined. If that issue is not properly solved, any progress is not possible for basic reasons.

When it is impossible to agree on approaches to a given concept and to define a single valid definition of a term (which I believe is rather a rule than an exception), a few different definitions peculiar to individual fields of ecology should be allowed (pluralistic approach), but such a state should be presented in a clear-cut manner and terminological differences should be articulated.

The second important recommendation, which should become an integral part of the research practice, is the one calling to observe the rules of scientific methodology. A researcher should be familiar with basic issues of methodology and philosophy of science as the quality of his work depends on that (e.g. Wiegleb 1989). In spite of the fact that some scholars seem not to acknowledge that relationship, a researcher should learn to think in terms of theories and hypotheses. They should also know what statistical analysis consist in and what it is used for. I do not mean the effective use of statistical software for performing due 
numerical calculations. The point is to understand the essence of statistical analysis and to not confuse research and null hypotheses.

The third important recommendation, which I believe should be rigorously observed, is the requirement to define our own research attitude. A researcher has to be aware of which ecological theory he identifies his approach with (there must be some!) and what are his premises. As it was already mentioned several times, most misunderstandings and related discussions result from failure to observe those three basic recommendations. In order to achieve the intended effect of those recommendations, ecologists should try to make their studies more formal in terms of methodology. Certainly, I am aware of the fact that making researchers observe that requirement may be difficult if you count just on the free will of the concerned parties. Therefore, I believe that editors of scientific journals might play a useful role here, enforcing formal rules of writing scientific papers, just like they do it now following the currently valid model. Certainly, the point is not to restrict the researchers' invention, but rather to teach them some discipline necessary for both arranging and reporting scientific studies. Of course forcing (let's not be afraid of this word!) a more formal approach may reduce the number of papers submitted for publication, but I believe that some reduction in joyful creativity may produce measurable benefits to all of us and the science we practise.

\section{Acknowledgments}

The author would like to thank Werner Ulrich for helpful comments and suggestions concerning this work.

\section{References}

Anand M., 1994, Pattern, process and mechanism - the fundamentals of scientific inquiry applied to vegetation science, Coenoses 9 (2): 81-92.

Chapleau F., Johansen P. H. \& Williamson M., 1988, The distinction between pattern and process in evolutionary biology: the use and abuse of the term "strategy", Oikos 53 (1): 136-138.

Eiten G., 1992, How names are used for vegetation?, J. Veg. Sci. 3: 419-424.

Gotelli N. J. \& McCabe D. J., 2002, Species co-occurrence: a meta-analysis of J. M. Diamond's assembly rules model, Ecology 83: 2091-2096.

Golley F. B., 1993, The history of the ecosystem concept in ecology, Yale Univ. Press.

Grace J. B. \& Tilman D. (eds.), 1990, Perspectives on plant competition, Academic Press, San Diego.
Heller M., 1992, Filozofia nauki. Wprowadzenie [Philosophy of science. Introduction], Wyd. Naukowe Papieskiej Akademii Teologicznej, Kraków.

Keddy P. A., 1987, Beyond reductionism and scholasticism in plant community ecology, Vegetatio 69: 209-211.

Keddy P. A., 1989, Competition, Chapman \& Hall, London - New York.

Lawton J. H., 1991, Ecology as she is done, and could be done, Oikos 61: 289-290.

Mason H. L. \& Langenheim J. H., 1957, Language analysis and the concept environment, Ecology 38 (2): $325-$ -340 .

Matejka K., 1992, Confusing of terms in ecology - an example of the ecotone polemic, Ekológia (ČSFR) 11(1): 99-102.

McIntosh R. P., 1967, The continuum concept of vegetation, Bot. Rev. 33: 130-187.

McIntosh R. P., 1975, Gleason - "individualistic ecologist", 1882-1975: his contributions to ecological theory, Bull. Torrey Bot. Club 102 (5): 253-273.

McIntosh R. P., 1985, The background of ecology: Concept and Theory, Cambridge University Press, Cambridge, England.

McIntosh R. P., 1993, The continuum continued: John T. Curtis' influence on ecology, [in:] J. S. Fralish, R. P. McIntosh \& O. L. Loucks (eds), John T. Curtis: fifty years of Wisconsin plant ecology, Wisconsin Academy of Science, Arts and Letters, Madison: 95-122.

Milne A., 1961, Definition of competition among animals, Symposia of the Society for Experimental Biology 15: 40-61.

Murray B. G., 1992, Research methods in physics and biology, Oikos 64: 594-596.

Peet R. K., 1974, The measurement of species diversity, Annual Rev. Ecol. Syst. 5: 285-307.

Peters R. H., 1980, Useful concepts for predictive ecology, Synthese 43: 257-269.

Peters R. H., 1991, A critique for ecology, University Press, Cambridge.

Price P. W., 1984, Alternative paradigms in community ecology, [in:] P. W. Price, C. N. Slobodchikoff \& W. S. Gould (eds), A new ecology: novel approaches to interactive systems, J. Wiley \& Sons, New York Chichester - Brisbane: 354-381.

Quenette P. Y. \& Gerard J. F., 1993, Why biologists do not think like Newtonian physicists, Oikos 68 (2): 361-363 .

Rejmánek M., 1977, The concept of structure in phytosociology with references to classification of plant communities, Vegetatio 35: 55-61.

Scheiner S. M., Hudson A. J. \& Van der Meulen M. A., 1993, An epistemology for ecology, Bull. Ecol. Soc. Am. 74 (1): 17-21. 
Shipley B. \& Keddy P. A., 1987, The individualistic and community-unit concepts as falsifiable hypotheses, Vegetatio 69: 47-55.

Stearns S. C., 1976, Life history tactics: a review of the ideas, Quart. Rev. Biol. 51: 3-47.

Stewart I., 1996, Czy Bóg gra w kości? Nowa matematyka chaosu [Does God play dice? New mathematics of chaos], Wydawnictwo Naukowe PWN, Warszawa.

Strong D. R., Jr., Simberloff D., Abele L. G. \& Thistle A. B. (eds), 1984, Ecological communities: conceptual issues and the evidence, Princeton University Press, Princeton.

Ulrich, W., 2004, Species co-occurrences and neutral models: reassessing J. M. Diamond's assembly rules, Oikos 107: 603-609.
Ulrich W., \& Gotelli N. J., 2007, Disentangling community patterns of nestedness and species co-occurrence, Oikos 116: 2053-2061.

Weiner J., 1995, On the practice of ecology, J. Ecol. 83: 153-158.

Werle J., 1992, Jedność przyrody - rzeczywistość czy iluzja? [Unity of the nature - reality or illusion?], [in:] Problemy Naukowe Współczesności [Scientific Problems of the Present Time], Ossolineum, Warszawa.

Wiegleb G., 1989, Explanation and prediction in vegetation science, Vegetatio 83 (1/2): 17-34. 